\title{
Lateral Transperitoneal Access to the Retropubic Space: A Surgical Alternative
}

\author{
Michael Anapolski, MD \\ Department of Obstetrics and Gynecology, Community Hospital Dormagen, \\ University of Witten-Herdecke, Dormagen, Germany. \\ E-mail: michael.anapolski@kkh-ne.de \\ Ibrahim Alkatout, MD, PhD \\ Department of Obstetrics and Gynecology, University Hospitals Schleswig-Holstein, \\ Campus Kiel, Germany.
}

\section{Stefan Soltesz, MD, PhD}

Department of Anesthesiology, Community Hospital Dormagen, Dormagen, Germany.

Sven Schiermeier, MD, PhD

Department of Obstetrics and Gynecology, University Witten-Herdecke, Witten, Germany.

\section{Thomas Papathemelis, MD}

Department of Obstetrics and Gynecology, St. Marien Hospital Amberg, Amberg, Germany.

\section{Dimitrios Panayotopoulos, MD}

Department of Obstetrics and Gynecology, Community Hospital Dormagen, Dormagen, Germany.

\section{Günter K. Noé, MD, PhD}

Department of Obstetrics and Gynecology, Community Hospital Dormagen,

University of Witten-Herdecke, Dormagen, Germany.

(c) Mary Ann Liebert, Inc. DOI: 10.1089/vid.2020.0003
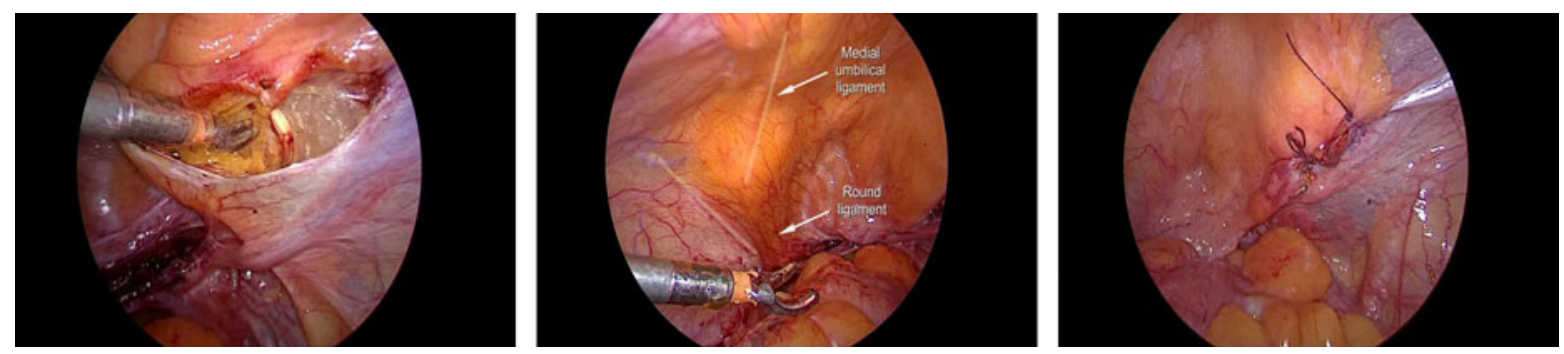

\section{Abstract}

Introduction: Many laparoscopic procedures in modern urogynecology require an access to the retropubic space. In view of controversies regarding the use of mesh implants for the repair of pelvic organ prolapse and the management of incontinence, laparoscopic interventions such as bladder neck colposuspension and lateral repair are gaining increasing attention among urogynecologists. A previous history of surgery in the area of interest may pose a serious challenge because it may be associated with significant scar tissue. Moreover, dissection of the retropubic space through the midline approach causes the bladder and the surrounding tissue to become detached from the abdominal wall. This tissue forms a dome-like structure that bulges into the abdominal cavity and might create an obstacle when the procedure is combined with other interventions. The access might restrict the surgeon's view when pectopexy—bilateral fixation of the cervix/vagina to pectineal ligaments ${ }^{1,2}$-or in-bag morcellation of uterine tissue ${ }^{3,4}$ are performed immediately afterward in the same session. We present a novel lateral approach to the retropubic space that overcomes the obstacles described earlier. 
Materials and Methods: Between January 2016 and December 2018, 343 interventions in the retropubic space-bladder neck colposuspension or lateral repair-were performed by the lateral transperitoneal approach. In 116 cases this access was chosen in combination with pectopexy or bilateral apical fixation. In 50 patients it was performed along with subtotal hysterectomy when in-bag morcellation was required, and 177 interventions included pectopexy as well as in-bag morcellation. Steps of surgery: The peritoneal layer is incised ventrally to the round ligament and the pectineal ligament or Cooper's ligament exposed by applying traction and countertraction. Blunt dissection is then continued along the pectineal ligament toward the symphysis, followed by unilateral exposure of the retropubic space. Dissection is performed using a bipolar grasper and scissors.

Results: No injury to the bladder, ureter, obturator nerve, or vessels occurred during surgery. No conversions to laparotomy were needed. In 342 cases the intervention was performed through the chosen route without significant blood loss $(<50 \mathrm{~mL})$. In one patient who had had no previous surgery in the area $(0.29 \%)$, the dissection had to be stopped because of bleeding from paravaginal vessels (blood loss $400 \mathrm{~mL}$ ). In this case the procedure was aborted; the scheduled procedure was completed 12 months later through an extraperitoneal access. In a retrospective setting, the exact operative time was difficult to evaluate. As a rule, the time demand for this step did not exceed 5 minutes per side.

Conclusions: In experienced hands, the lateral transperitoneal access to the retropubic space is a safe procedure with a low risk of complications. This approach extends the portfolio of the laparoscopic surgeon and enables him/her to modify the retropubic access to the patient's personal anatomy and the technical features of the scheduled intervention.

Patient Consent: The author(s) have received and archived the patients' consent for video recording/ publication before video recording of the procedure.

Authors' Contributions: M.A., I.A., and G.K.N. were in charge of project development, data collection, article and video writing/editing; D.P. did data collection; S. Soltesz, S. Schiermeier, and T.P. performed article writing/editing.

No competing financial interests exist.

Runtime of video: 6 mins 27 secs

Keywords: accessing retropubic space, space of Retzius, colposuspension, lateral repair, in-bag morcellation, pectopexy

\section{Cite this video}

Michael Anapolski, Ibrahim Alkatout, Stefan Soltesz, Sven Schiermeier, Thomas Papathemelis, Dimitrios Panayotopoulos, Günter K. Noé, Lateral Transperitoneal Access to the Retropubic Space: A Surgical Alternative, Videourology. 2020, DOI: 10.1089/vid.2020.0003.

\section{References}

1. Noe KG, Spuntrup C, Anapolski M. Laparoscopic pectopexy: A randomised comparative clinical trial of standard laparoscopic sacral colpo-cervicopexy to the new laparoscopic pectopexy. Short-term postoperative results. Arch Gynecol Obstet 2013;287:275-280.

2. Noe KG, Schiermeier S, Alkatout I, Anapolski M. Laparoscopic pectopexy: A prospective, randomized, comparative clinical trial of standard laparoscopic sacral colpocervicopexy with the new laparoscopic pectopexy-postoperative results and intermediate-term follow-up in a pilot study. J Endourol 2015;29:210-215.

3. Anapolski M, Panayotopoulos D, Alkatout I, et al. Power morcellation inside a secure endobag: A pilot study. Minim Invasive Ther Allied Technol 2016;25:203-209.

4. Anapolski M, Panayotopoulos D, Alkatout I, Soltesz S, Schiermeier S, Noe G. Preclinical safety testing for morcellation and extraction for an endobag with sealable ports: In vitro pilot study. Surg Endosc 2017;31:494-500.

Original Publication Date: 2020 